\title{
REVIEWS
}

\section{ESSENTIALS OF INDUSTRIAL HEALTH}

By E. O. Sappington, M.D., Dr.P.H.

(Lippincott Company, Philadelphia and London. 1943. Pp. 626. Illustrated. 42s.)

Very few books on industrial medicine have been published in this country, so this new volume will prove useful as a book of reference for the established medical officer and a helpful guide to those new to industry. While the subject matter is culled from American experience the figures quoted and the views expressed may stimulate industrial medical officers in this country to investigate many of their own problems in a similar manner to that adopted in the U.S.A. Although we were pioneers in the improvement of industrial working conditions, and much American legislation has been based on the experience of our Factory Department, descriptions of the type of industrial medical service of many American companies suggest that on some points they have outstripped us. The author takes the realistic view that industrial health service pays handsomely and gives figures to support this.

The book is divided into three main parts. Part one, on industrial health administration, covers the history of industrial medicine, occupational morbidity and mortality. The scope and objectives of industrial health, the type of knowledge required by the industrial medical officer, and the organization of medical services for small and large factories are given in detail. Part two, on industrial hygiene and toxicology, is valuable in that it classifies the various types of industrial health exposure, giving lists of materials and circumstances likely to affect health with a description of the clinical picture and the trades in which such dangers are encountered. The way to survey plants with simple methods of sampling and analysis should prove helpful in controlling and maintaining control of working conditions. Planned sanitation and hygiene for workers including co-ordination of industrial and community health services are described in detail. Part three deals with industrial medicine and traumatic surgery and covers methods of co-ordinating the worker's physical and mental make-up with the job he has to do. Causes of industrial accidents and occupational disease are estimated and their control and treatment described. The importance of prevention is the keynote of this book. The author at every stage stresses the value of keeping adequate records and, what is far more important, the use to which such records can be put.

W. E. C.

\section{A GUIDE FOR THE TUBERCULOUS PATIENT} By G. S. Erwin, M.D.

(William Heinemann, London. 1944. Pp. 112. 3s. 6d.)

Dr. Erwin has fulfilled a great need by supplying this useful book for the tuberculous patient. It explains in simple language the nature of the disease and the conditions which are necessary for its successful treatment. To do this is a most important part of the treatment of any chronic disease which does not completely incapacitate the patient. It is specially important at the present time when, rightly, attention is focussed on the employment of the disabled. Pulmonary tuberculosis incapacitates more people in the prime of their working life than any other disease. On choice of work, however, Dr. Erwin states that 'individual advice should be sought from the sanatorium medical officer.' These doctors can certainly advise on the patient's response to work and exercise but probably have had little experience of work in most industries. It is certain that consultation between the industrial medical officer and the sanatorium medical officer would result in better advice than could be given by either alone. On the subject of food in the sanatorium, Dr. Erwin implies that there is often complaint and suggests that the patient is at fault. Food can, and should be, served well and attractively to the sick, but one fears that in many public institutions this is not done. Surely, therefore, rather than condemn the patient it would be better to stimulate a movement to provide appetizing food in such places. The book achieves its object and can be recommended to those for whom it is written. There must be many working in industry who would be glad to know that it has been published.

K. M. A. P.

\section{THE JOURNEY TO WORK}

By K. Liepmann, Ph.D.

(International Library of Sociology and Social Reconstruction. Kegan Paul, Trench, Trubner and Co. London. 1944. Pp. 204. 15s.)

'Travelling ...' states the Barlow Report (p. 91), ' can hardly fail to have adverse effects on health and to result in fatigue (and) loss of energy. . . . There can be little doubt, too, that these adverse effects on the workers are reflected in no small measure on their efficiency and output and in turn, on the employers' cost of production.' Industrial medical officers will agree with these words quoted by Dr. Liepmann, but will understand her comment that this statement is founded on a general impression and not on exact knowledge as there have been previously no special investigations published on the subject. There are certain benefits to the worker resulting from an ability to travel to his job, says the author; it 'helps him in getting the right job, in retaining a suitable job, in combining two intermittent (seasonal) jobs and in changing over from declining to flourishing industries, and in 'the prevention of frequent migration of individuals and families. The worker's family as a whole benefits from the varied employment of its members and domestic life is enriched by a variety of occupational interests among the family.' It is also true, however, as Mr. Carr Saunders says in his admirable preface, that " less attention is perhaps paid to the positive evils arising from daily travel. It is not merely that time is wasted, it is not just that so many hours are lost from the day. To many daily travel is a cause of nervous fatigue; the zest of a new day is worn off before it has begun. More than that, no faculty can be properly exercised while travelling in crowds, it is difficult to read, to observe, to concentrate or to contemplate with any profit. The necessity of passing so much time each day during which profitable activity is difficult or impossible encourages the habit of passing all leisure time in this way. The daily journey to work is one of the features of modern life making for depersonalisation and accounts in some degree for the inability of men nowadays to enjoy themselves in creative activity or, indeed, in any fashion which demands more than passive response.'

Valuable charts are given showing in scale maps the residential distribution of employees of representative London and Birmingham factories.

Turning to the wider problems surveyed in this book Dr. Liepmann deals at length with the present problems 